\title{
Bacteriological evaluation of a down-draught necropsy table ventilation system
}

\author{
W Al-Wali, C C Kibbler, J E McLaughlin
}

\begin{abstract}
Aims-To evaluate the microbiological efficacy of a down-draught necropsy table ventilation system (which surrounds the cadaver with a "curtain" of air under continuous extraction) during post mortem procedures.

Methods-Air sampling was carried out both in the presence and absence of staff and cadaver and during a full post mortem procedure, with functioning and non-functioning table air extraction. The penetration of the air "curtain" was also examined during the use of an oscillating bone saw by means of a tracer organism, Bacillus subtilis var niger, painted on to the skull.
\end{abstract}

Results-There was little difference between bacterial counts obtained in the presence of staff only, staff plus cadaver, or during a post mortem examination. With all counts obtained, however, there was a two to three-fold reduction when the ventilation was in operation compared with when the extract duct was occluded. Using the tracer organism, a two to three $\log$ reduction in counts was shown when the "curtain" was in operation during the use of the oscillating bone saw.

Conclusions-These results suggest that the system provides potential protection for post mortem room staff against airborne infections.

(F Clin Pathol 1993;46:746-749)

A few studies have highlighted the risk of infection to staff working in post mortem rooms. ${ }^{1-6}$ The most commonly recorded infections are pulmonary tuberculosis, hepatitis $B$, and non-A, non-B hepatitis. Wound and gastrointestinal infections occur less frequently. Other potential hazards include HIV infection, viral haemorrhagic fever, other viral infections, and Creutzfeldt-Jacob disease.

Most of these infections are probably acquired by direct contact or following puncture wounds, although dissemination of Mycobacterium tuberculosis in air and on to surrounding surfaces has been shown during the slicing of infected lung. ${ }^{7}$ Pulmonary tuberculosis in post mortem room staff is most likely acquired by inhalation. There is little evidence that blood-borne infections are spread in air, although there is some indirect evidence for aerosol transmission of hepatitis
B. ${ }^{8}$ More recently, airborne dissemination of HIV has been demonstrated in an experimental model investigating possible aerosol transmission from high speed drills in the operating theatre setting. ${ }^{9}$ Consequently, there is some concern that certain procedures, including the use of mechanical saws in the post mortem process, might disseminate infectious agents.

One means of minimising potential airborne spread of infection is to use a post mortem isolator tent, but this is cumbersome, reduces visibility, and increases the time required for the procedure. ${ }^{10}$ Local exhaust extraction has been suggested as another means of hazard reduction. A ventilated post mortem table applies this principle on a large scale, surrounding the whole cadaver with a curtain of air under continuous extraction. There is little published evidence to show that their use induces significant reduction in the numbers of airborne organisms and so the extra cost of such tables has not been considered justified. The design of the first tables produced also made them difficult to clean. We describe our experience with a newly designed system recently installed at the Royal Free Hospital.

\section{Methods}

POST MORTEM ROOM VENTILATION SYSTEM

To overcome some of the problems associated with the previously available ventilated necropsy tables three $207.5 \times 75.5 \mathrm{~cm}$ tables were constructed to a new design by Afos Ltd., Hull, in collaboration with one of us (JEMcL) and, together with three Afos ventilated dissection tables, these were installed in the refurbished post mortem room in 1989. The table design allows air to be extracted around the perimeter of the whole table through three rows of $1.27 \mathrm{~cm}$ diameter holes surrounding the working surface of the head half of the table and two rows surrounding the foot half. The general post mortem room ventilation system was designed in collaboration with Ronald Lear and Associates, Cheshunt, Herts, to provide a general downwards displacement of air in the room. Fresh air entry into the room is provided through a ceiling grid with the entire extract ventilation of the room through the six tables. This maintains the room at negative pressure and ensures that an air extract is always closer to the source of contamination than the operator. The extract from each necropsy table is linked to the extract from its associated dis- 
section table and an adjustable damper is provided so that the entire extract ventilation can pass through two pairs of tables or all three. With air extraction switched through two pairs of tables, the flow rate through the necropsy table is set at $0.566 \mathrm{~m}^{3} /$ second and through the dissection table at $0.212 \mathrm{~m}^{3} /$ second. Some air is additionally extracted into an adjacent storage area at $0.271 \mathrm{~m}^{3} /$ second, giving a total extraction rate for the post mortem room of $1.828 \mathrm{~m}^{3} / \mathrm{second}$ under all conditions. With this system the air exchange rate in the post mortem room is 30.6 air changes/hour.

The tables were designed to be easily cleaned with liquid waste draining into a sump below the working surface where it is diluted with running water and run off under gravity towards a sump drain. The pedestal is fitted with a hydraulic lift to allow the working height of the table to be easily adjusted.

\section{AIR SAMPLING}

Air samples were collected using a Casella slit sampler. The sampler was used to collect air samples at 2 minute intervals (1400 litres air per sample) on to blood agar plates. These were taken at the four corners of one of the post mortem tables which had been selected at random for the whole study. Above each point samples were taken from three different heights, table height $(0 \mathrm{~cm})$, cadaver height $(20 \mathrm{~cm})$, and post mortem staff head height $(80 \mathrm{~cm})$. Four samples were taken at each height and the mean colony counts obtained. Samples were taken in the following situations: (1) when the examining staff were alone in the room without the cadaver; (2) in the presence of staff and cadaver; (3) during the post mortem examination.

A complete set of samples was taken with the extraction port in the table occluded and a further set with it fully open.

The dispersal of bacteria when opening the skull was investigated using a tracer organism Bacillus subtilis var niger (NCTC 10073). A suspension containing $10^{8}$ spores $/ \mathrm{ml}$ was painted on to the outer surface of the skull and the bone cut with a De Soutter M 170 oscillating saw. Air samples were taken in

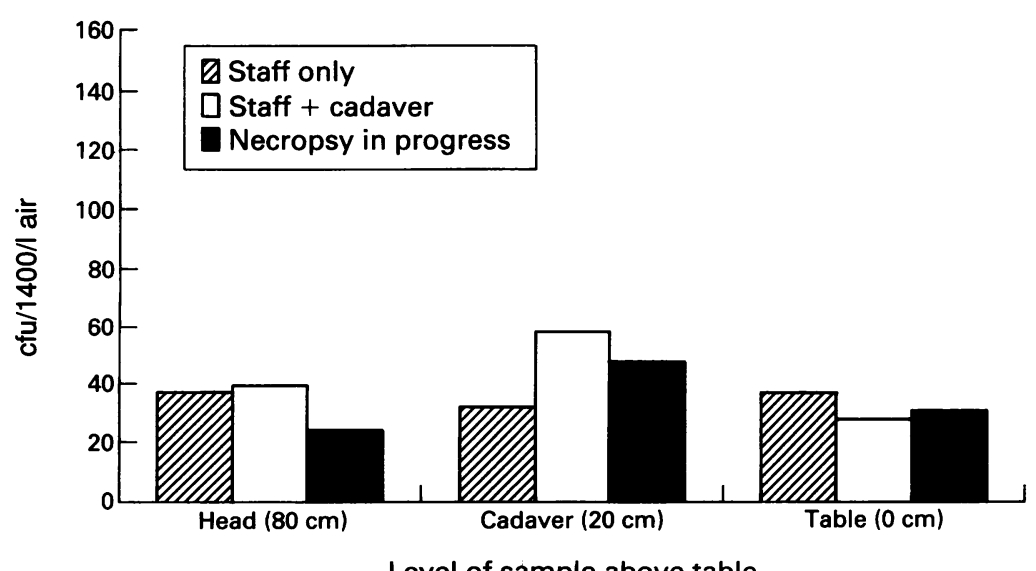

Figure 1 Post mortem room air samples: ventilation on (mean total aerobic counts). duplicate above the corners of the head end of the table. Settle plates were also exposed at six different places in the post mortem room: (a) beneath the post mortem table; (b) on the post mortem table within the "curtain"; (c) on a trolley $2 \mathrm{~m}$ away at a height of $70 \mathrm{~cm}$; (d) on the dissecting table $2.5 \mathrm{~m}$ away; (e) on a basin $3 \mathrm{~m}$ away at a height of $75 \mathrm{~cm}$; (f) in a corner of the room at a distance of $3.6 \mathrm{~m}$.

\section{MEASUREMENT OF AIR FLOWS}

Air flow above the table was measured using a hot wire anemometer (Airflow Developments Ltd., High Wycombe, Bucks). Air flow at table level was measured by placing an anemometer (Griffin and George, Loughborough, England) on the necropsy table so that the $7.0 \mathrm{~cm}$ diameter aperture of the instrument covered five ventilation holes at the head end and four at the foot end of the table. Additional measurements were made at the quarter and three-quarter points on each side, as well as at the mid-point of the foot and head end of the table. Air movement was monitored by means of smoke testing. Smoke was continuously produced by a smoke generator placed on the table until a steady state had been achieved. Cold smoke was also intermittently released from smoke tubes (MSA Ltd., East Shawhead, Coatbridge, Scotland) at a height of $20 \mathrm{~cm}$ above the table and $20 \mathrm{~cm}$ away from the edge at two points one-third and two-thirds of the distance along each side of the table.

The blood agar plates were incubated aerobically for 24 hours at $37^{\circ} \mathrm{C}$ and for a further 48 hours to detect fungi. All organisms were identified using standard laboratory methods.

\section{Results}

\section{AIR SAMPLING}

The mean total aerobic colony counts/1400 1 of air at the different heights above the post mortem table with and without the ventilation in operation are shown in figs 1 and 2 . The total counts did not exceed 144/1400 1 air in the absence of air extraction and were reduced between two and three-fold when the ventilation was in operation.

The organisms isolated were coagulase negative staphylococci, Staphylococcus aureus, Micrococcus spp Bacillus spp and filamentous fungi. Gram negative bacteria were isolated on only one occasion.

The mean counts of the tracer organism $B$ subtilis var niger are shown in fig. 3. The effect of the local air extraction was to reduce the counts from $>10^{3 / 1400}$ litres air to $13^{13 / 1400}$ litres air. The settle plate counts increased from a maximum of 5 bacterial colonies during a sample period of 60 minutes when the room was empty to 140 colony forming units (all coliforms) on the plate beneath the table when a post mortem examination was in progress in the absence of ventilation.

AIR FLOW

Air was found to be moving downwards at a velocity of $0.2 \mathrm{~m} / \mathrm{second} 20 \mathrm{~cm}$ above the surface of the table and smoke testing showed 


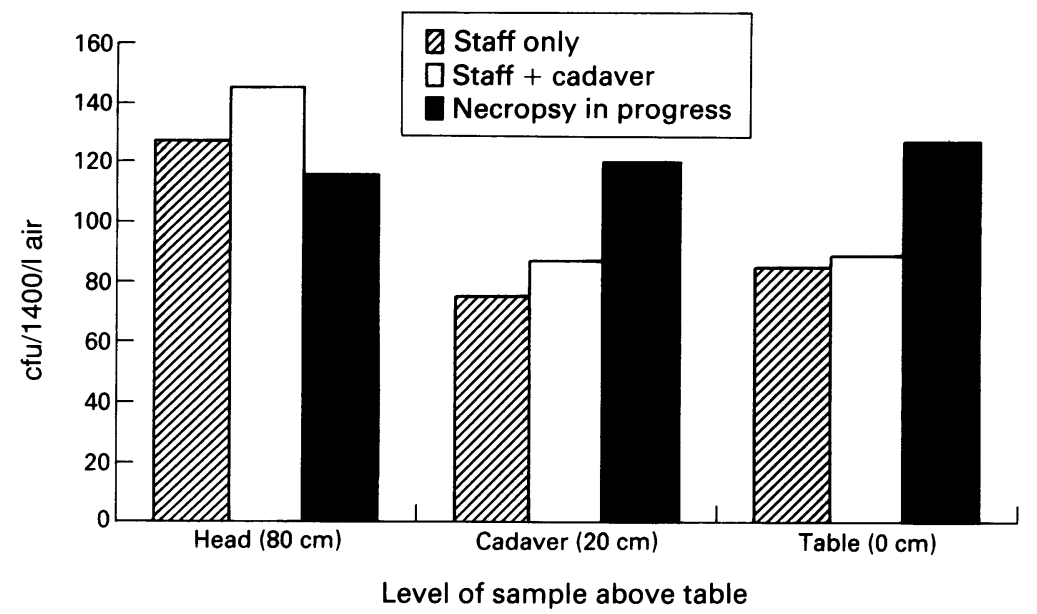

Figure 2 Post mortem room air samples: ventilation off (mean total aerobic counts).

that smoke released $20 \mathrm{~cm}$ above the table was readily drawn in towards the air inlets and disappeared within 10 seconds. Smoke produced at the level of the table was contained within the perimeter of the table. At the level of the table the mean air velocity was $2.240 \mathrm{~cm} / \mathrm{second}$ where there were three rows of holes, $1.928 \mathrm{~m} /$ second where there were two, and $3.383 \mathrm{~m} / \mathrm{second}$ over the drainage ports giving a mean air extraction rate of $0.644 \mathrm{~m}^{3} / \mathrm{second}$. A possible reason for the measured value being higher than the figure specified in the design is that, in use, the working surface of the linked dissection table is $40 \%$ covered by a cutting-up board and organ tray.

\section{Discussion}

The potential benefits of a down-draught ventilation system in the post mortem room would appear to be two-fold: a reduction in the ambient concentrations of formalin; and other volatile substances, and the provision of some protection against the microbiological hazards of post mortem procedures.

Eradication of unpleasant odours, as well as objective evidence of reduced concentra-

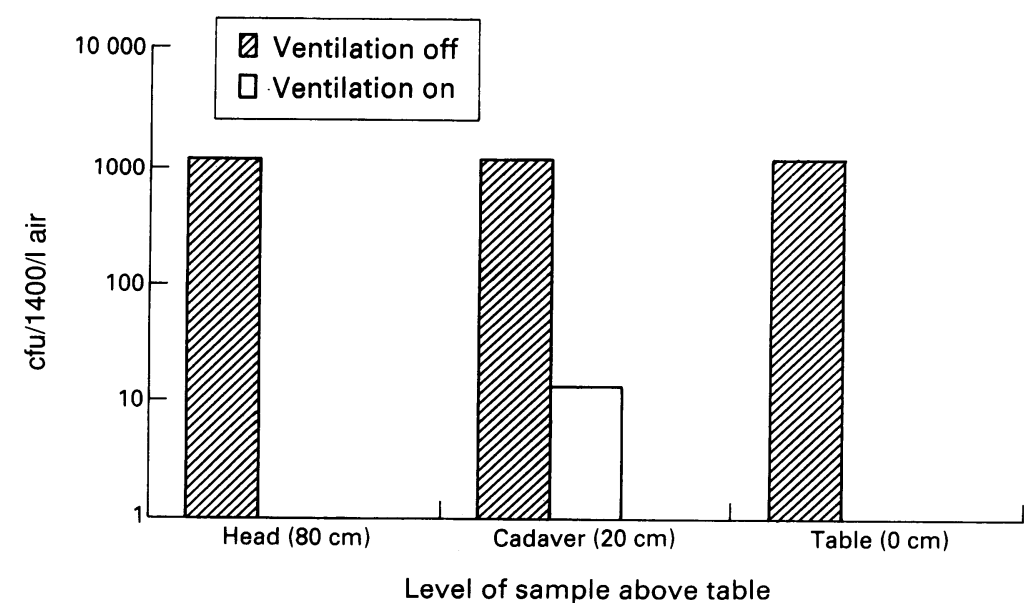

Figure 3 Post mortem room air samples while using Saw (mean B subtilis counts). tions of formalin has already been demonstrated during use of ventilated specimen tables of similar design. ${ }^{11}$ This has been borne out by the considerable experience with the full Afos table system since its installation at the Royal Free Hospital, and this aspect alone is felt by the users of the system to be of considerable benefit. Until now, however, there has been no evidence that the system will reduce the numbers of micro-organisms associated with post mortem procedures. A previous study examined airborne microorganisms in a variety of different post mortem rooms including one facility with two Pland down-draught mortuary tables. There was no significant effect on the bacterial content of sampled air, but no attempt was made to examine the dissemination of organisms from within the "air curtain". ${ }^{12}$

A recent detailed study of post mortem rooms using an identical sampling method ${ }^{10}$ to ours showed very little difference in the counts obtained in rooms with different airchange frequencies (including those with no mechanical assisted ventilation). Indeed, the authors noted that the total counts related more to the number of persons present than to the procedure performed. Our study, likewise, showed little difference in the total counts whether the cadaver was present or not, or whether or not a procedure was under way. The use of the table ventilation did produce a two or three-fold reduction in total counts at all levels above the table, but it is doubtful whether such a reduction in inoculum would prevent transmission of infection even if these organisms had all been contributed by the cadaver.

The organisms isolated when the ventilation was in use were almost all skin organisms (coagulase negative staphylococci, Bacillus spp and Micrococcus spp), confirming Babbs's findings and providing further evidence that staff organisms were the major contributor to the total counts. The use of the cranial saw might be expected to generate relatively high velocity particles which could escape the ventilation "curtain". But, the ventilation appeared to prevent passage of all tracer organisms except at cadaver height (the point at which the velocity of particles at the "curtain" would be expected to be highest). Overall, the system achieved a two to three log fall in counts, suggesting a significant protective benefit for post mortem room staff. It is possible that similar results could be achieved by using a saw with integral extraction ventilation, but such a unit introduces further equipment to the post mortem room which is itself difficult to clean.

We have found these tables to be no more difficult to clean than other types of stainless steel table. During use the constant washing of the sump keeps the under surfaces clean and at the end of the post mortem examination the simple design facilitates the final cleaning.

No attempt was made in this study to examine the effect on viruses or mycobacteria, but it is reasonable to speculate that parti- 
cle transmission of these organisms should be reduced in a similar manner by this system. There is no conclusive evidence that either hepatitis B or HIV-1 infections have caused infection in post mortem room workers via the airborne route, but there is support for transmission of pulmonary tuberculosis to post mortem room staff via this route. ${ }^{5-7}$ Fortunately, the numbers of staff who have been infected are small, but this fact is likely to preclude a prospective clinical study to examine the microbiological efficacy of these tables. The data obtained from this study certainly suggest potential efficacy and it does not seem appropriate for these ventilated tables to be dismissed as "unnecessary". ${ }^{10}$ Whether they represent an economical means of providing low level exhaust ventilation and working surfaces will largely depend on whether the design of the post mortem suite permits inexpensive installation of the necessary ceiling and underfloor ducting.

Although the use of a ventilated post mortem table seems to provide potential health and safety benefits for staff it must be borne in mind that the most important route for transmission of blood borne infections is via penetrating sharps injuries. All attempts should be made to avoid these by adopting procedures recommended in the current Health and Safety Advisory Committee guidelines (HSAC 1991).

We are grateful for the help and cooperation given by $\mathrm{Mr} \mathrm{C}$ Marriage and Mr J Levinski during the course of this study. We additionally thank Mr JM Caygill and Mr C Bristow for providing the smoke generator.

1 Grist NR, Emslie JAN. Infections in British clinical labo-

2 Grist NR, Emslie JAN. Infection in British clinical laboratories 1984-85. J Clin Pathol 1987;40:826-9.

3 Grist NR, Emslie JAN. Infections in British clinical labo-

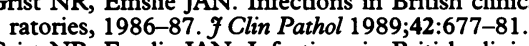

4 Grist NR, Emslie JAN. Infections in British clinical laboratories, 1988-89. F Clin Pathol 1991;44:667-9.

5 Harrington JM, Shannon HS. Incidence of tuberculosis, hepatitis, brucellosis and shigellosis in British medical laboratory workers. $\mathrm{Br} \mathrm{Med} \mathrm{F} \mathrm{1976;1:759-62.}$

6 Sugita M, Tsutsumi Y, Suchi M, Kasuga H, Ishiko T. Pulmonary tuberculosis. An occupational hazard for pathologists and pathology technicians in Japan. Acta Pathol fapn 1990;40:116-27.

7 Reid DD. Incidence of tuberculosis among workers in medical laboratories. Br Med $\mathcal{f} 1957$;ii:1-14.

8 Dienstag JL, Ryan DM. Occupational exposure to hepatitis $B$ virus in hospital personnel: Infection or immunization? Am F Epidemiol 1982;115:26-39.

9 Johnson GK, Robinson WS. Human immunodeficiency virus-1 (HIV-1) in the vapours of surgical power instruments. f Med Virol 1991;33:47-50.

10 Babb JR, Hall AJ, Marlin R, Ayliffe GAJ. Bacteriological sampling of post mortem rooms. $f$ Clin Pathol 1989;42:682-8.

11 Kelly JD, McLaughlin JE. The application of downdraught ventilation systems in the pathology laboratory draught ventilation systems in the pathology laboratory
and post-mortem room. Health Estate fournal 1990;44: and post

12 Newsom SW, Rowlands C, Matthews J, Elliot CJ. Aerosols in the mortuary. $\mathcal{F}$ Clin Pathol 1983;36:127-32.
Clin 


\section{Book Review}

Solar and Ultraviolet Radiation. IARC Monographs on the Evaluation of Carcinogenic Risks to Humans. Vol 55. (Pp 316; Sw fr. 65.) World Health Organization. 1992. ISBN 92-832-1255-X

This book, which conforms to the usual high standards of IARC monographs, provides a detailed account of the biophysics of ultraviolet and solar irradiation and their biochemical actions on DNA. There is much about their intriguing biological effects on cellular responses and repair, and a critical review of their tumorigenic, local immunosuppressive, and other harmfu effects-for example, in causing cataract and "solar keratosis". Fluorescent lighting is reviewed and is regarded as an unproved carcinogenic risk for man, but improper use of sunbeds is shown to be harmful. Sun screens are briefly discussed, too.

There is rightly much concern about the risks to man of excessive ultraviolet and solar irradiation. This book provides the facts to support the drive to protective measures, and at the same time it is a valuable source of information about the neglected areas of radiation pathology and toxicology.

A D DAYAN

\section{Notices}

\section{Quality'93 \\ Raising quality in the NHS: what progress?}

\section{November London}

Quality '93 follows the success of Raising Quality in the NHS held in March 1992.

Quality '93 is being organised by the BMA, the $B M \mathcal{A}$, the Kings Fund, the College of Health and Quality in Healthcare. The meeting will review progress with raising quality in the NHS and also look at what's new in raising quality. A particular focus will be on involving patients in raising quality.

The meeting is open to doctors, nurses, all health professionals, managers, politicians, researchers, policy makers, and members of the public.

\section{For further details contact:}

Pru Walters, BMA House, Tavistock Square, London WC1H 9JP. Telephone: 0713836518 .
Charing Cross and Westminster Medical School

\section{MRCPath Part One}

Diagnostic Histopathology Course

\section{0-24 September 1993}

This intensive five day course at Charing Cross Hospital:

- covers all important and problem areas in systemic pathology;

- consists of lectures, slide seminars and demonstrations;

- includes three evening sessions on special techniques;

- includes a course dinner.

The numbers of places on the course will be limited so early application is recommended.

The course fee $(£ 365)$ includes student accommodation, breakfast, coffee, tea and lunch on each day, and the course dinner. If accommodation and breakfast are not required, the course fee will be $£ 300$.

For further details and application forms, please contact:

Professor Kristin Henry, Department of Histopathology, Charing Cross and Westminster Medical School, Fulham Palace Road, London W6 8RF.

Tel: 0818467133 Fax: 0818461364

The Royal College of Pathologists

\section{ME E T I N G S}

Advances in Breast Pathology -

Relevance to Management and Prognosis

Wednesday 17 November 1993

Diagnostic Developments in Leukaemia and Lymphoma

Wednesday 19 fanuary 1994

Perspectives in Good Laboratory Management

Tuesday 22 February 1994

all at

The Royal College of Pathologists, 2 Carlton House Terrace, London SW1

The meetings are open to members and non-members of the College.

Further details and application forms can be obtained from

Scientific Meetings Officer, RCPath,

2 Carlton House Terrace, London SW17 5AF

Tel: 0719305862 ext 24/26.

\section{4th Breton Workshop on Autoimmunity}

\section{Brest, 15-16 April 1994}

Sjögren's syndrome (J F Bach, H M Moutsopoulos and N Talal); systemic lupus erythematosus (E M Tan, D Alarcón-Segovia and $G$ Friou); rheumatoid arthritis (R N Maini, I M Roitt and J Sany).

Official languages: English and French, with simultaneous translation.

Call for abstracts. Deadline for receipt of abstracts: 15 March 1994. Will be published in Clinical Experimental Rheumatology.

Secretariat: Laboratory of Immunology, Brest University Medical School Hospital. Tel: (33) 98223384 .

Fax: (33) 98801076.

\section{Association of Clinical Pathologists} Junior Membership

Junior membership of the Association is available to medical practitioners who have been engaged in the practice of pathology for a period of less than four years. Junior members are able to remain in this category for a maximum of six years or on the attainment of consultant status. The annual subscription is $£ 34$ for those resident in the United Kingdom and $£ 65$ for those overseas. The annual subscription may be claimed against tax.

Junior members receive the fournal of Clinical Pathology each month. Other benefits are reduced registration fees to attend ACP scientific meetings, all the documents regularly sent to full members of the Association including ACP Nezus, which has a regular column for juniors, and the twice yearly summary of pathology courses included in the ACP programme of postgraduate education. Junior members have their own representative body, the Junior Members' Group, which has a direct input to Council.

For Junior Membership apply to: The Honorary Secretary, Association of Clinical Pathologists, 221 Preston Road, Brighton BN1 6SA. (0273) 561188.

\section{Errata}

The following errors appeared in:

Bacteriological evaluation of a downdraught necropsy table ventilation system by McLaughlin et al, $\mathcal{F}$ Clin Pathol 1993; 46:746-9: the third paragraph of the Results section should read:

The mean counts of the tracer organism $B$ subtilis var niger are shown in fig 3 . The effect of the local air extraction was to reduce the counts from $>10^{3 / 144001}$ air to 13/1400 l air.

The settle plate counts increased ...

On page 748 :

The mean air velocity at the level of the table should read $2 \cdot 240 \mathrm{~m} / \mathrm{second}$ and not $2 \cdot 240 \mathrm{~cm} /$ second as currently printed. 